\title{
REPERCUSSÕES DE UM CURSO DE FORMAÇÃO CONTINUADA A DISTÂNCIA EM MATEMÁTICA NA VISÃO DOS PARTICIPANTES
}

\author{
REPERCUSSIONS OF A CONTINUED DISTANCE TRAINING COURSE IN \\ MATHEMATICS IN THE DISTANCE VIEW OF THE PARTICIPANTS
}

\author{
Vicente Henrique de Oliveira Filho \\ Pontifícia Universidade Católica de São Paulo - PUC-SP, enriqueoliver2005@yahoo.com.br
}

\section{Gilberto Tavares dos Santos}

Universidade Federal do Rio Grande do Sul - UFRGS, gilberto.tavares@ufrgs.br

\section{Resumo}

Este artigo apresenta os resultados de uma pesquisa que avaliou as repercussões de um curso de matemática, realizado a distância, como formação continuada de professores dos anos iniciais do Ensino Fundamental. Dezoito professores participaram da pesquisa. Para coletar os dados, utilizaram-se questionários, entrevistas semiestruturadas, documentos relacionados ao curso realizado e memoriais construídos pelos docentes ao longo da formação. Para analisar os dados coletados, utilizou-se a Análise Textual Discursiva, de Moraes e Galiazzi (2011), delineada em quatro etapas: organização do corpus, unitarização dos elementos de significado, definição das categorias e produção de metatexto. Da análise elaborada, emergiram duas categorias de importância, intituladas "Qualificação da prática pedagógica" e "Aprimoramento da formação inicial". Os resultados evidenciaram que o curso de formação continuada contribuiu para qualificar a formação dos professores e a sua prática pedagógica. Neste sentido, destaca-se a importância de promover espaços formativos e socializadores de conhecimento, visando a uma formação que integre e articule diferentes saberes e, ao mesmo tempo, admita as singularidades dos sujeitos no seu processo de formação.

Palavras-chave: Formação continuada de professores; Formação a distância; Identidade profissional docente; Ensino e aprendizagem da matemática.

\begin{abstract}
This article presents the results of a research that evaluated the repercussions of a distance learning math course as continuing teacher training in the early years of elementary school. Eighteen interviewed teachers attended the research. To collect the data, questionnaires, semi-structured interviews, documents related to the course carried out, and memorials built by the teachers throughout the training were used. To analyze the data collected, we used the Discursive Textual Analysis, by Moraes and Galiazzi (2011), outlined in four stages: organization of the corpus, unitization of the elements of meaning, definition of categories and production of metatext. From the elaborated analysis, two categories of importance emerged, entitled Qualification of the pedagogical practice and Improvement of the initial
\end{abstract}


formation. The results showed that the continuous training course contributed to qualify the teachers' training and their pedagogical practice. In this sense, the importance of promoting formative and socializing spaces of knowledge is highlighted, aiming at a formation that integrates and articulates different knowledge and, at the same time, admits the singularities of the subjects in their formation process.

Keywords: Continuing teacher training. Continuing education at a distance. Teaching professional identity. Math's teaching and learning.

\section{Introdução}

Uma das dificuldades verificadas na relação entre docente e discente diz respeito ao ensino e à aprendizagem de Matemática. Não raro, a disciplina é tida como obrigação curricular, não se percebendo a utilidade que os seus conteúdos possam ter para a compreensão do cotidiano. Há dificuldade em se promover a associação entre teoria e prática. Muitas vezes não fica claro para docentes e discentes que o conhecimento matemático é um produto cultural presente em diversos momentos das nossas vidas, tais como trocas comerciais, identificação de espaços, cálculo de quantidades de itens a adquirir etc, desde as atividades mais simples até as mais elaboradas. Contudo, independente do grau de complexidade envolvido, é fato que a matemática auxilia a compreender o mundo que nos cerca.

A despeito das dificuldades surgidas para aprimorar o ensino e a aprendizagem da matemática, mudanças sociais mobilizam os professores permanentemente. Uma das principais transformações deve-se à presença cada vez mais frequente de recursos tecnológicos para auxiliar a vida das pessoas. Ao professor surge o desafio de caracterizar a nova realidade, buscando qualificar-se permanentemente para dar suporte aos discentes.

Com o intuito de renovar, a formação continuada emerge como uma possibilidade de o professor refletir sobre sua prática pedagógica e ressignificá-la, construindo estratégias de ensino que contemplem as demandas dos dias atuais e contribuam para qualificar o sistema de educação no seu todo.

Ciente da importância da formação continuada de professores, em 2010 foi oferecido pelo MEC um Programa de Formação Continuada em matemática para implementação nas escolas públicas estaduais e municipais com os professores dos anos iniciais do Ensino Fundamental. $O$ curso foi planejado como formação continuada de caráter reflexivo, buscando valorizar as experiências pessoais e profissionais do professor e produzir novos enfoques para o ensino de matemática (MURTA et al., 2008). O programa de formação tinha os seguintes objetivos: (a) oferecer suporte à ação pedagógica dos professores do ensino fundamental, (b) propor situações de reflexão e construção de conhecimentos em processo contínuo de formação, (c) desenvolver conhecimentos que possibilitassem a compreensão dos conteúdos, (d) incentivar a cultura da formação continuada, e (e) desencadear formação continuada em rede pelo país (BRASIL, 2010, p.1).

O curso foi planejado para ser desenvolvido na modalidade semipresencial, com utilização de material impresso para realizar encontros presenciais e a distância. $O$ curso 
teve duração de um semestre letivo, totalizando 24 encontros presenciais de 4 horas/aula cada. Após cada encontro presencial, havia um intervalo de uma semana, durante a qual os alunos realizavam, a distância, a leitura do material impresso do curso, registrando suas dúvidas para serem discutidas no encontro seguinte. Durante o curso, os participantes elaboraram um projeto de ensino e o aplicaram junto aos seus alunos. Ao final do curso, os resultados foram apresentados ao grande grupo.

Ao se propor um curso de formação continuada para professores, sempre surgem questionamentos acerca dos impactos dos mesmos na prática dos docentes: Tais cursos contribuem efetivamente para qualificar os processos de ensino e de aprendizagem? Quais as contribuições desses cursos? Que modificações podem ocorrer na prática docente a partir desses cursos? Partindo de tais questionamentos, delineou-se esta pesquisa, que teve como objetivo geral avaliar as repercussões de um curso de formação continuada a distância em matemática na visão de dezoito dos seus participantes.

Para sistematizar o levantamento das percepções dos professores, utilizou-se a Análise Textual Discursiva (ATD) proposta por Moraes e Galiazzi (2011), detalhada em quatro etapas: (i) organização do corpus, (ii) unitarização dos elementos de significado, (iii) definição das categorias, e (iv) produção de metatexto.

O texto a seguir caracteriza-se pela apresentação do tema inerente ao desenvolvimento deste trabalho, da metodologia de pesquisa utilizada e das considerações finais acerca dos resultados obtidos.

\section{A formação inicial e continuada de professores}

Vivemos tempos de interconexão social e tecnológica. Essa ligação emerge de forma imediata e os avanços são rapidamente percebidos e assimilados pela sociedade. Essas mudanças são profundas e amplas ao mesmo tempo, de caráter incerto, dada a rapidez com que ocorrem e os questionamentos que suscitam. Faz-se necessário, por isso, compreender o funcionamento dessa sociedade, por meio de estudos e debates, para desenvolver nas pessoas capacidades básicas e específicas que lhes permitam refletir, participar e tomar decisões com relação às novas regras de convivência. Por isso, é urgente formar e preparar as pessoas para esse grau de incerteza que se configura (ALARCÃO; TAVARES, 2001).

Neste contexto, cabe à escola, atrelada às políticas públicas de formação e valorização docente, contemplar uma formação que assimile as mudanças sociais emergentes e repercuta na qualidade do ensino oferecido aos estudantes. Pela escola perpassam os questionamentos, as vivências e teorias, de forma que, agregadas, gerem modificações que conduzam a sociedade a um modo de melhor viver (MORAES, 1997).

Se a escola precisa acompanhar e promover a discussão das mudanças sociais, o papel do professor assume posição de destaque nesse contexto, pois a educação é entendida como prática social em uma construção inacabada. $O$ ofício de um professor é complexo e precisa estar integrado à atualidade (MOITA, 2013). Ele aprende seu ofício estudando as teorias e as associa às próprias experiências. Trata-se de uma profissão que 
pressupõe o exercício de sensibilidade, intuição, escuta e, de maneira geral, proximidade com a vida, a fim de promover o ensino e a aprendizagem (ARROYO, 2013).

No sentido de fortalecer o papel do professor, a sua capacitação, no decorrer do tempo, torna-se imprescindível, sendo considerada um processo evolutivo que pressupõe a assimilação das descobertas e significados à consciência e às atitudes, de maneira fortuita ou organizada, em qualquer espaço social (JOSSO, 2010). A formação é influenciada pelos contextos interno, a escola, e externo, a comunidade, de modo que um afeta e é afetado pelo outro, de forma negativa ou positiva. Para que prevaleça o aspecto positivo, é preciso que a escola esteja focada nas suas duas principais vocações: a de exercer o seu papel social e a de promover ensino e aprendizagem enquanto espaço comum de consecução de saberes e fazeres (NÓVOA 2009).

Delineada a interação positiva entre escola e comunidade, a formação docente é considerada um processo contínuo, no qual as ações e reflexões surgidas configuram o fazer da formação e são consideradas como um processo transformador em um constante ir e vir, não se podendo identificar momentos pontuais de recomeços ou rupturas (GUÉRIOS, 2005). Borges (2012) recomenda que a formação docente seja provida de conhecimentos educacionais e culturais vastos e que possibilite ao professor atuar com desenvoltura em situações pedagógicas atípicas e desafiadoras, já que a realidade se apresenta de maneira mutante e diversificada. Para o autor, precisa-se, na prática, de uma formação que integre e articule ao mesmo tempo as interpelações sociais e a singularidade do sujeito. Imbernón (2010, p. 10) afirma que "para que seja significativa e útil, a formação precisa ter um alto componente de adaptabilidade à realidade diferente do professor".

Analisando o processo contínuo e ininterrupto de qualificação, Martins (1999 apud MARÇAL, 2012) ordena a formação docente em quatro etapas no tempo, quais sejam: (1) pré-treino, que alavanca as experiências vivenciadas pelo professor enquanto aluno e que poderão auxiliar na sua formação, (2) formação inicial, que lhe possibilita conhecimento pedagógico-didático para exercer suas atividades, (3) iniciação, correspondente aos primeiros anos subsequentes à formação inicial, em que várias formas de aprendizagem de sobrevivência são utilizadas na prática, e (4) formação contínua, como meio de desenvolvimento e aperfeiçoamento profissional permanente.

A formação inicial prepara o docente para assumir a sua profissão, assegurada por titulação prevista em lei (BORGES, 2012). Para Imbernón (2001), a formação inicial pode ser entendida como meio de desenvolvimento profissional, pois busca habilitar o futuro professor para assumir a tarefa educativa em toda a sua diversificação e complexidade. Trata-se de uma necessidade de qualificação ajustada às necessidades dos diversos níveis de ensino. Porém, não pode ser reconhecida como etapa de caráter meramente acadêmico e obrigatório. Esse tipo de formação transcende o nível burocrático do seu cumprimento, atende a um compromisso de introdução à profissionalização do docente e apoia os processos de formação subsequentes.

Esteve (2014) salienta que essa formação deve permitir ao futuro professor exercer as habilidades de: (a) reconhecer-se como professor, (b) identificar os estilos de ensino que pode utilizar, (c) pesquisar sobre os efeitos que tais estilos reproduzem nos discentes, (d) 
caracterizar problemas cotidianos em sala de aula, a fim de associá-los aos conteúdos teóricos, e (e) resolver os problemas surgidos por decorrência das atividades de ensino e aprendizagem.

No Brasil, a partir da lei 9.394/96, exige-se nível superior como formação inicial para atuar na educação básica, por meio de cursos de licenciatura. Para a educação infantil e ensino fundamental, nos seus anos iniciais, requer-se a licenciatura em Pedagogia, salvo excepcionalidades a locais onde a condição não possa ser atendida (BRASIL, 2013). Gatti (2010) apresenta algumas fragilidades identificadas na realização desses cursos: (1) fragmentação do currículo proposto, (2) abordagens descritivas que não se preocupam em relacionar adequadamente teorias e práticas, (3) proposta de ensino mais teórico do que prático, (4) ementas de disciplinas mais preocupadas em justificar "o por que" ensinar e pouco explicativas quanto à "o que" e "o como" ensinar, (5) baixa proporção de horas dedicadas às disciplinas de formação profissional específica, (6) conteúdos das disciplinas discutidos eventual e superficialmente, (7) reduzido número de cursos que aprofundam conteúdos relacionados à educação infantil, e (8) não integração das universidades com as escolas de ensino fundamental e médio.

A preparação de professores foi durante muito tempo considerada apenas como o período de formação inicial. Entretanto, surgia permanentemente a perspectiva de atualização, aperfeiçoamento e apropriação de novos conhecimentos e que ocorriam ações complementares à formação inicial, com enfoque de aprimoramento da ação já iniciada (IMBERNÓN, 2010). Borges (2012) afirma que a formação inicial cumpre uma etapa que se conclui, porém requer complementação, haja vista que o conhecimento é dinâmico e carece de ser discutido ininterruptamente. Já Falsarella (2004, p. 50) entende a formação continuada como "proposta intencional e planejada, que visa à mudança do educador por meio de um processo reflexivo, crítico e criativo de sua própria prática pedagógica, produzindo conhecimento e intervindo na realidade".

Neder (2004) aponta quatro princípios político-pedagógicos a serem levados em conta para a implementação de cursos de formação continuada: (a) estar o processo de formação intrinsecamente ligado ao projeto pedagógico da escola, (b) ser a prática profissional a referência para a sua realização; (c) haver articulação entre formação inicial e continuada; (d) promover a associação entre a formação e a construção da identidade profissional do professor.

Para o docente, a formação continuada é necessária por vários motivos, dentre os quais se destacam: (1) como forma de reavaliar e reconstituir a sua prática, pois ele precisa estar preparado e disposto a correr riscos e aberto para novos aprendizados; (2) como possibilidade de fortalecer uma relação recíproca entre o ensinar e o aprender, em um ciclo inconcluso que se renova periodicamente com o acréscimo de novos saberes; (3) como meio de desenvolver a capacidade crítica dos sujeitos envolvidos e possibilitar-lhes a compreensão do contexto social em que estão inseridos, e (4) como ideia clara de quais as consequências das suas ações no campo docente (GATTI, 2013).

A função da formação continuada é também fortalecer a identidade profissional do docente, a partir de uma proposta de desenvolvimento de saberes. O professor constrói o 
seu ideário profissional referenciado em suas escolhas e crenças epistemológicas sobre 0 conhecimento, ou seja, suas maneiras de selecionar, produzir e apreender novos saberes da prática docente e integrá-los como construto de uma formação profissional ao longo da vida. Para isso ocorrer, há a necessidade de ele estar aberto à atualização constante dos saberes, às novas aprendizagens e fazeres inerentes à prática educativa, para que não sucumba à obsolescência e desvalorização profissionais (GUIMARÃES, 2005).

Assim como na formação inicial, as legislações que orientam a formação continuada são a Lei 9.394/96 e o Plano Nacional de Educação (PNE) 2001-2010. Segundo o PNE, a formação continuada dos professores da educação básica deve garantir o desenvolvimento pessoal e profissional do docente, sendo também considerada parte importante na estratégia de melhoria permanente da prática educacional por meio de reflexão técnica, ética e política.

Para viabilizar as metas estabelecidas pelo PNE foram definidas pelo MEC várias ações, dentre elas a criação do Sistema Universidade Aberta do Brasil (UAB), cujo objetivo principal é promover a formação inicial e continuada de professores, gestores e trabalhadores que atuam na educação básica, assim como pessoas com dificuldade de acesso à formação universitária, por meio da metodologia da educação a distância. 0 sistema funciona normalmente em parceria entre Governo Federal, Estados e Municípios (GATTI, 2009).

Na prática, a formação continuada tem se apresentado em dois formatos. Um mais específico, em que são disponibilizados cursos estruturados e formais ofertados após a formação inicial. O outro formato é mais amplo, quando abrange horas de trabalho coletivo nas escolas, reuniões pedagógicas, participação em congressos, seminários etc (GATTI, 2008 apud BORGES, 2012).

Não obstante a sua contribuição enquanto possibilidade de proporcionar conhecimentos atualizados aos docentes e disseminá-los para a sociedade, os cursos de formação continuada apresentam também limitações, quais sejam (GATTI, 2013): (1) objetivos não claramente definidos, comprometendo a problematização e significação dos conteúdos; (2) condições técnicas e materiais insatisfatórios para atender às atividades propostas, dado o tempo curto em que, às vezes, os cursos são realizados; (3) ausência de modificações concretas no processo de ensino, (4) avaliações não realizadas ou analisadas sem subsidiar futuras ações; (5) falta de conexão entre os resultados obtidos com o planejamento das formações subsequentes; (6) apresentação de conteúdos teóricos e práticas não integrados; (7) desconhecimento acerca da diversidades sociais de atuação; (8) não continuidade da formação, (9) objetivos de ação futura não explicitamente definidos; (10) turmas de formação muito heterogêneas, que dificultem a discussão e reflexão; (11) a formação vista mais como uma ação burocrática - uma obrigação - do que como um suporte à renovação de conhecimento e ao exercício da atividade profissional; (12) um ritual de apresentação dos conteúdos dissociado das realidades sociais do docente e discente, e (13) prioridade à formatação do processo em detrimento da valorização e promoção da reflexão, crítica e autonomia do docente. 
Em resumo, a formação docente, tanto a inicial quanto a continuada, deve acompanhar os movimentos da sociedade. A escola precisa renovar-se e o professor é o objeto da formação. A formação continuada não prescinde da formação inicial, pois ambas se complementam; porém, cada uma apresenta seus propósitos especificamente delineados, conforme disposto anteriormente.

\section{Metodologia da pesquisa}

O estudo realizado é de natureza qualitativa, do tipo estudo de caso (YIN, 2005; GIL, 2009). Contou com a participação de um grupo de dezoito professores que atuam nos anos iniciais do Ensino Fundamental de Matemática, participantes de um curso de formação continuada. Foram escolhidos por conveniência de proximidade física, a fim de possibilitar contato direto entre pesquisador e respondentes. Dez dos entrevistados começaram na profissão apenas com o curso de magistério. Oito deles iniciaram já com o curso de licenciatura. Atualmente, todos têm formação superior. Os professores exercem atividade na carreira docente há, em média, 13 anos.

Os dados foram coletados por meio de um questionário on line, de uma entrevista semiestruturada realizada ao término do curso e de um memorial constituído ao longo do mesmo. Para a análise, utilizou-se a Análise Textual Discursiva (ATD), proposta por Moraes e Galiazzi (2011), delineada nas etapas: (a) organização do corpus da análise textual, (b) unitarização dos elementos de significado, que é a desconstrução do corpus, (c) definição das categorias, a partir do agrupamento de elementos de significado semelhantes, e (d) produção final de metatexto.

Na prática, o corpus levantou uma primeira compreensão relativamente ao objetivo da pesquisa. A unitarização fragmentou o corpus e identificou os elementos de significado expressos nas falas dos entrevistados e de interesse para a pesquisa. Do corpus foram extraídos os elementos de significado, que deram origem a duas categorias: qualificação da prática pedagógica e aprimoramento da formação inicial.

A seguir é detalhada a composição das duas categorias dimensionadas com a aplicação da ATD. Apresentam-se as principais citações dos dezoito sujeitos de pesquisa, associadas a conceitos e argumentos que buscam evidenciar o objetivo pretendido. As identidades dos sujeitos de pesquisa foram mantidas sob sigilo e substituídos por nomes fictícios.

\section{Qualificação da prática pedagógica}

As práticas pedagógicas constituem-se em um rol de possibilidades de ação para que o docente desafie o aluno a aprender. Para implementá-las, o professor precisa ter conhecimento do conteúdo que será abordado, da prática em si, seu funcionamento, suas possibilidades de adaptação e flexibilização, e do grupo a quem será destinada. Nóvoa (2009) avalia que o sucesso no desenvolvimento da prática pedagógica pelo professor é uma forma de reconhecer a sua aplicação em contexto social próximo à realidade do discente. Ou seja, é preciso que a prática faça sentido para o discente de forma que ele 
converta a experiência em uma possibilidade de utilizá-la no seu dia-a-dia. $O$ autor acrescenta ainda que esse tipo de vivência proporciona maior assimilação dos conteúdos a serem apreendidos.

Os professores entrevistados destacaram a importância do curso como possibilidade de aprender novos conhecimentos, refletir sobre as tarefas a serem propostas aos alunos e modificar as dinâmicas do ensino em sala de aula.

Com relação à aprendizagem de novos conhecimentos, Anne relata:

Para mim o curso foi interessante, sim, porque evoluí mais no meu trabalho na sala de aula, pois você tem que ter conhecimentos além do que você já tinha, tem de estar apto a atualizações [...]. Foi uma ótima oportunidade de refletir sobre minhas aulas, me comunicar e saber o que os colegas estão fazendo nas suas escolas.

Para Anne, seu trabalho como docente evoluiu a partir das ações pedagógicas abordadas no curso e serviu para estimular a reflexão sobre a sua prática docente. Ela ratifica a necessidade de estar atualizada diante das demandas sociais e também reconhece a importância de interagir com outros participantes como forma de também construir conhecimento. Seu depoimento vem ao encontro do entendimento de Falsarella (2004) sobre a formação continuada como possibilidade de mudar o comportamento do docente por meio de um processo reflexivo, crítico e criativo.

Carla comenta sobre o curso afirmando: "[...] me deu essa visão de refletir sobre a minha prática e, a partir disso, discuti-la com os colegas de curso, contribuindo para construir minha identidade profissional". Evocou ainda a necessidade da interação e das trocas de experiências entre os sujeitos em formação bem como a consequente construção de espaços vivenciais e coletivos pelo professor no ambiente escolar.

Imbernón, (2009, p.76), afirma que "a identidade profissional é dinâmica, não uniforme e se gesta na relação entre o contexto no qual o trabalho se realiza e o próprio trabalho em si". Para o mesmo autor, "compartilhar dúvidas, contradições, problemas, sucessos e fracassos são elementos importantes na formação das pessoas e no seu desenvolvimento pessoal e profissional". De fato, o professor aprende no coletivo e constrói sua identidade profissional a partir de trocas experienciais mútuas.

A professora Marlise afirma:

Ao longo da realização do curso, tive a oportunidade de ampliar meus conhecimentos e saberes para melhorar a qualidade da aprendizagem dos alunos [...]. Gostei muito da proposta da escrita e da leitura em matemática para usar nas séries iniciais do ensino fundamental.

A mesma docente afirma a relevância da oportunidade de ampliar conhecimentos e reconhece seu aprendizado relativamente a interpretar os conteúdos por meio da escrita e leitura matemáticas. Percebe-se na sua fala a importância desse estímulo voltado aos docentes que atuam como professores polivalentes nas séries iniciais do Ensino Fundamental. 
[...] senti-me muito motivado após a realização do curso, pois aprendi muitas coisas e atualizei muitas outras com muita profundidade [...]. No início, eu não acreditei muito na proposta a distância, porque faríamos as atividades sozinhos, mas em cada encontro presencial eu me senti motivado, pois houve muitos momentos para trocarmos ideias e aprender muitos conceitos. Espero que outros cursos sejam feitos dessa forma, pois é bom manter contato com outros professores, só que o professor precisa rever seu papel para se adaptar às tecnologias e apresentá-las para os alunos [...]. Agora, as aulas podem ser apresentadas fora da sala de aula e isso é muito interessante.

Para Sérgio, o curso possibilitou-lhe construir novos conhecimentos e aprofundar outros que já dominava. Seu comentário vai ao encontro do que diz Gatti (2013), referindose à formação continuada como possibilidade de o docente constituir e reavaliar suas práticas e conhecimentos. Além disso, o professor salienta que o formato do curso (EaD) estava adequado, apesar da sua desconfiança inicial, pois surgiram possibilidades de os docentes se encontrarem pessoalmente para interagir. Por fim, ele argumenta que o professor precisa ter o seu papel revisto em decorrência das mudanças tecnológicas e de as aulas acontecerem de forma virtual em diferentes locais e tempos de realização. $O$ depoimento de Sérgio é coerente com o pensamento de Litwin (2001), que diz ser a EaD uma oportunidade de aprendizado em que relações não-convencionais ocorrem entre professor e aluno, já que ambos não convivem no mesmo espaço enquanto o processo de ensino e aprendizagem se concretiza.

Relativamente à constatação sobre refletir acerca das tarefas a serem propostas em aula, Anne explica:

Com o curso concebeu-se caráter reflexivo para o ensino e aprendizagem, que considera o professor sujeito da ação, valorizando suas experiências pessoais, suas incursões teóricas, seus saberes da prática, além de possibilitar-Ihe que atribua novos significados à prática e ainda compreenda e enfrente as dificuldades com as quais nos deparamos no dia-a-dia [...]. Houve incentivo para que usássemos exemplos do nosso dia-a-dia e dos alunos para que eles reflitam com os exercícios em sala de aula [...]. Esse é o grande aprendizado que eu levo do curso.

A mesma professora explicita a importância do curso de formação para "despertar" para a reflexão, associando experiências pessoais, conteúdos teóricos e práticas pedagógicas com o objetivo de incentivar ações educativas mais elaboradas e criativas para lidar com as dificuldades cotidianas. Para ela, o legado do curso está na constatação acerca da possibilidade de essa forma reflexiva poder acontecer na prática docente cotidiana. Nesse sentido, o curso pode ser considerado como alavancador da oportunidade de reflexão acerca do ensino e da aprendizagem de matemática.

De fato, o curso propôs a reconfiguração da prática docente tendo como objetivos oferecer suporte à ação pedagógica, propor situações de reflexão e construção de conhecimentos em processo contínuo de formação, desenvolver conhecimentos que 
possibilitem a compreensão dos conteúdos, incentivar a cultura de formação continuada e desencadeá-la em rede pelo país (BRASIL, 2010).

Por sua vez, André afirma:

Quando iniciei o curso, tive que encarar muitos desafios, dificuldades, mas apareceram boas ideias e sugestões, [...] porque os conhecimentos foram se modificando. Na medida em que o tempo foi passando, fui me integrando com outros professores e com o conteúdo do curso [...] . Fui percebendo a proposta de realizar as atividades com reflexão para dar significado às práticas pedagógicas e reavaliando minhas posições em sala de aula.

Está presente na narrativa de André que ele teve dificuldades no início do curso. Porém, a sua percepção sobre o conhecimento foi se modificando, à medida que foi interagindo e intercambiando conhecimento com seus pares, até assumir a possibilidade de ressignificar as suas práticas pedagógicas no sentido de realizá-las com mais reflexão. Alarcão (1996) afirma que o professor reflexivo faz de sua prática pedagógica um campo de reelaboração contínua, com a associação entre a teoria e a prática enquanto estruturadora das suas futuras ações.

Roberta afirma que, por meio do curso, foi capaz de:

[...] considerar conteúdos a que não dava tanta relevância e buscar meios de tratá-los com novas práticas de ensino. Senti necessidade de enriquecer minhas práticas e avaliar os resultados dessas ações para os alunos. [...] os contatos com outros professores me ajudaram bastante nessa visão de enxergar as práticas pedagógicas com mais criatividade. [...] os exercícios que fizemos em conjunto foram muito bons.

Roberta explica que ter realizado o curso desafiou-a a rever a sua atuação, principalmente com relação ao uso de práticas pedagógicas em aula. Percebe-se um "redespertar" do senso crítico com implicações na forma de atuar e a necessidade de avaliar o seu trabalho. Infere-se a importância de ter realizado o curso, interagido com outras pessoas e ter tido acesso a outros procedimentos didáticos que podem lhe servir de incentivo para melhorar a qualidade do processo de ensino e aprendizagem de matemática. Como afirma Freire (2014, p. 40) "é pensando criticamente a prática de hoje ou de ontem que se pode melhorar a próxima prática".

No tocante às melhorias nas dinâmicas de ensino apresentadas em sala de aula, a professora Madalena afirma:

[...] foi durante o curso que tive a oportunidade de repensar conhecimentos em relação aos conteúdos trabalhados em sala e, a partir daí, melhorar ainda mais a minha prática de ensino. O curso deu-me essa visão de refletir sobre a prática matemática e de discutir com os colegas de curso sobre possibilidades de redimensionar a atuação em sala de aula e reelaborar novos posicionamentos para estimular o aprendizado.

Fica explícito no comentário de Madalena que, por meio das discussões em grupos de trabalho durante o curso, ela obteve subsídios necessários para refletir sobre a sua prática pedagógica. $E$ isso foi positivo, pois os debates realizados despertaram nela 0 
ímpeto de promover modificações. Madalena ainda considerou que os debates efetivados durante o curso contribuíram para a construção da identidade profissional dos professores. Essa fala é validada por Imbernón (2010) quando argumenta que um dos pilares da formação continuada é a troca de experiências e a reflexão entre indivíduos iguais que têm o objetivo de se atualizar e melhorar a comunicação entre si.

Débora explica:

[...] sempre fui muito preocupada em realizar um trabalho que fosse eficaz, e busquei inserir de uma forma natural o conteúdo de aprendizagem do curso no contexto do educando, [...], procurava colocar as atividades na rotina de sala de aula, refletia para entender qual era a proposta, não como uma metodologia, mas, como uma maneira de melhorar a prática pedagógica a partir das reflexões, e com a inserção dos temas.

A fala de Débora expressa sua vontade de ultrapassar as limitações tecnicistas de meramente executar uma atividade em sala de aula. Para isso, preocupou-se em compreender as atividades propostas e apresentá-las aos discentes. Buscou adaptar os conteúdos à realidade dos alunos e promover reflexão acerca do que se estava propondo. Schon (2000) afirma que o docente é capaz de reconstruir os saberes e fazeres inerentes ao exercício da docência. O ofício do professor exige domínio de conteúdos e dinamismo para que ocorra conhecimento na ação, reflexão na ação, reflexão sobre a ação e reflexão sobre a reflexão na ação. Na prática, a inserção de uma temática em sala de aula é possível a partir da reflexão internalizada e introjetada sobre a ação, decorrendo daí a reformulação da ação em procedimentos reflexivos sucessivos.

Constata-se, portanto, que o curso incentivou a aprendizagem de novos conhecimentos e promoveu a reflexão pelos docentes com subsequentes alterações na dinâmica do trabalho das suas aulas. Na visão dos professores participantes, o curso de formação continuada possibilitou reverem suas práticas pedagógicas e refletirem acerca da importância de compreender a matemática no cotidiano.

Os professores tiveram a oportunidade de aprimorar a sua formação, tendo sido capazes de desconstruir equívocos quanto a alguns conteúdos até então ministrados. Eles consideram que os aprendizados do curso têm colaborado para o exercício das suas atividades na atualidade. De acordo com os relatos, o curso foi fundamental para os docentes refletirem sobre as suas ações em sala de aula e os saberes necessários para atuar nos anos iniciais do ensino Fundamental. Constatou-se que os relatos dos professores apontam para a conscientização acerca da necessidade de utilizar procedimentos didáticos que favoreçam o protagonismo dos estudantes e a reflexão crítica sobre a realidade como meio de melhorar os resultados de aprendizagem.

\section{Aprimoramento da formação inicial}

A formação inicial é o requisito mínimo exigido do futuro professor nos cursos de graduação em licenciatura nas diferentes áreas do conhecimento. Veiga (2014) assinala que a formação inicial objetiva orientar e fortalecer o docente para o exercício profissional enquanto agente socializador do processo de aprendizagem. Todavia, a formação do 
professor não se encerra com a formação inicial. Para Imbernón (2010), o docente precisa reconstruir seu mosaico formativo e ressignificar fazeres e saberes às suas práticas profissionais no decorrer do tempo.

Os docentes expressaram em suas respostas a importância de aprimorar e dar novo sentido à formação inicial. Bernadete explicita sua experiência inicial com o ensino da matemática, relembrando:

[...] quando comecei a lecionar sentia bastante dificuldade em lidar com alguns conteúdos e mostrá-los para os alunos. Muito me ajudou o curso. Penso que os professores deveriam sempre ter cursos de formação continuada nas disciplinas, pois existem certos conteúdos que são complicados. É uma oportunidade de ouvir a opinião dos colegas e rever a forma de apresentar os conteúdos. [...] gostei muito do curso, mas tenho medo de que ele não seja repetido.

Bernadete atribui dificuldades iniciais na sua formação e reivindica formação continuada como reforço para disciplinas cujos conteúdos são difíceis de assimilar e que acabaram não sendo aprendidos por ela. Argumenta ser essa uma oportunidade de reconstruir o processo formativo não realizado adequadamente. Por fim, ela mostra-se receosa de que formações continuadas não voltem a acontecer.

Ao abordar o curso de formação continuada, Roberta afirma:

[...] quando eu cheguei à sala de aula, senti-me praticamente só, estava concluindo o curso de Letras [...], fui chamada no concurso e me veio aquele bombardeio de ideias para aplicar, mas quando cheguei para alfabetizar fiquei aterrorizada, não sabia como fazer isso. E quando começou o curso interessei-me bastante, pois consegui visualizar na teoria as situações que tinham me acontecido na prática. E senti mais segurança para poder atuar, pois eu não fiz nenhum treinamento desde a faculdade.

O depoimento de Roberta aponta um sentimento de insegurança no período inicial das suas atividades, quando ela teve muitas ideias, porém não conseguiu executá-las. Em seu entendimento, a formação inicial não foi suficiente para o exercício da atividade que the cabia. Possivelmente, o impasse começou a ser superado tão logo a atividade profissional teve início, por iniciativa própria, já que ela não participou de qualquer tipo de formação desde a conclusão da graduação. O curso serviu-Ihe de motivação para compreender situações enfrentadas anteriormente e sentir-se mais confiante para atuar no futuro profissional.

Carla, por sua vez, relata:

[...] como eu estava no início da profissão, para mim tudo foi novidade. Deparei-me com uma realidade muito diferente, porque eu nunca tinha ido para uma sala de aula. Eu fiz pedagogia, mas a minha prática não foi em sala de aula, foi um projeto, ministrado para professor que estava na sala de aula. Pensei até em desistir, não fiz isso não sei por quê, tive muitas dificuldades. Eu fiz o curso para melhorar minha prática pedagógica em sala de aula.

Já Débora comenta: 
[...] na época, eu estava com uma turma de alunos de $5^{\circ}$ ano. O curso facilitou o meu trabalho com as operações matemáticas, as crianças começaram a participar das aulas e a gostar. [...]. Até concluir a graduação eu não tive nenhuma disciplina ligada ao ensino da matemática, eu falo por mim, que fiz Pedagogia.

Carla e Débora, licenciadas em Pedagogia, fizeram o curso de formação continuada com o objetivo de melhorar suas práticas em aula e ampliar seus conhecimentos matemáticos. Neste sentido, Curi (2005) aponta a complexidade e a competência extra requerida para o pedagogo ensinar matemática nos anos iniciais, visto que os cursos de formação inicial de professores não contemplam conhecimentos específicos para tal finalidade.

A análise das respostas dos professores entrevistados evidencia que eles reconhecem o êxito da formação continuada como aprimoramento da formação inicial. $A$ aprovação fica manifesta no uso das expressões "muito me ajudou", "segurança para atuar", "melhorar minha prática" e "facilitou o meu trabalho" como resultados do curso de formação continuada. Contrariamente à avaliação positiva, aparecem as expressões "bastante dificuldade", "não sabia como fazer", "tive muitas dificuldades" e "não tive nenhuma disciplina ligada ao ensino da matemática" associadas à formação inicial. Os depoimentos evidenciam a importância da formação continuada como aprimoramento da formação inicial, possivelmente porque, agora, os docentes têm ideia mais clara a respeito do exercício da profissão, suas exigências e dificuldades.

A despeito de as limitações relatadas sobre a formação inicial se referirem mais a questões curriculares do que a deficiências do curso, a percepção é a de que a formação inicial deixou lacunas no que se refere ao exercício da atividade docente. Há, porém, que se considerar as peculiaridades que distinguem os propósitos de cada tipo de formação. $A$ formação inicial ocorre em um momento da vida quando os professores ainda não começaram a carreira. Esse tipo de formação busca abordar conceitos e práticas pedagógicas para subsidiar o exercício futuro da profissão.

Evidenciou-se que a temática tratada no curso foi importante para a mudança na dinâmica de atuação dos participantes, pois sua formação inicial não lhes dera suporte suficiente para sua atividade profissional. Ademais, o curso foi uma oportunidade para os professores repensarem coletivamente o conhecimento matemático em termos de conteúdos e procedimentos didáticos a abordar. A necessidade de apresentar a matemática contextualizada à realidade dos alunos é um pensamento dominante entre eles, pois vários exemplos práticos foram relatados. Percebe-se a vontade dos professores em aprimorar suas práticas, refletir sobre os conteúdos e sua abordagem, bem como contribuir para qualificar a aprendizagem dos estudantes. Por fim, houve reconhecimento da proposta de realização do curso a distância, porém com encontros presenciais predefinidos, em cujas datas se faziam explanações principalmente sobre as modificações que cada um estava realizando após o curso ter sido iniciado.

\section{Considerações finais}


A pesquisa desenvolvida comprovou que o curso de formação continuada realizado pelos docentes foi uma ótima oportunidade para troca de experiências, revisão de conteúdos teóricos, reflexão sobre a prática e atualização sobre procedimentos didáticos. A proposta do curso teve ampla aceitação, pois embora tenha sido um curso a distância, permitiu aos participantes terem encontros presenciais nos quais eles puderam trocar experiências.

Os participantes manifestaram a necessidade de promover eventos dessa natureza que sejam de fato "continuados" e não pontuais. Manter o ciclo de encontros é, portanto, muito importante para revitalizar o papel do professor e fortalecer a sua identidade profissional. Alguns docentes reconheceram que o curso lhes permitiu rever conceitos que compreendiam com dificuldade desde o período da sua formação inicial. Alguns admitiram que durante a realização do curso procuraram se aproximar mais dos alunos, buscando identificar suas necessidades e dificuldades e criando estratégias para contemplá-las.

É necessário acreditar que cada docente possa ser o agente de transformação do seu próprio conhecimento, sentindo-se participante ativo dos processos de ensino e aprendizagem. Um desafio a ser superado nas relações estabelecidas entre quem ensina e quem aprende. Nesta perspectiva, os cursos de formação continuada de professores precisam incentivar a escola a ser um espaço formativo e socializador de conhecimento. Precisa-se de uma formação que integre e articule diferentes saberes e, ao mesmo tempo, admita as singularidades dos sujeitos no seu processo de formação.

Espera-se que a formação continuada se configure como um espaço para troca de experiências, reflexão sobre a prática, apropriação de novos conhecimentos e novas formas de pensar a educação diante das demandas da contemporaneidade. Como consequência, acredita-se que a identidade profissional docente seja fortalecida no decorrer desse tempo, e que consequentes avanços na qualidade da educação da população também venham a acontecer.

\section{Referências}

ALARCÃO, I. (Org.). Formação reflexiva de professores: estratégias de supervisão. Porto Portugal. Porto Editora. 1996.

ALARCÃO, I.; TAVARES, J. Paradigmas de formação e investigação no ensino superior para o terceiro milênio. IN: ALARCÃO, Isabel. (Org.). Escola reflexiva e nova racionalidade. Porto Alegre: Artmed. 2001.

ARROYO, M.G. Ofício de mestre: imagens e auto-imagens. Petrópolis, RJ: Vozes. 2013.

BORGES, L. F. F. Um currículo para a formação de professores. In: VEIGA, I. P. A. DA SILVA, E. F. (Org.) A escola mudou. Que mude a formação de professores. 3 ed Campinas, SP: Papirus. 2012.

BRASIL. Ministério da Educação. Secretaria da Educação Básica. Guia Geral PróLetramento: programa de formação continuada de professores dos anos/séries iniciais do ensino fundamental: matemática: fascículo do tutor e encartes. Brasília: MEC/SEB. 2010. 
BRASIL. LDB: Lei de Diretrizes e Bases da Educação Nacional: Lei no 9.394, de 20 de dezembro de 1996 [recurso eletrônico]. - 8 ed. - Brasília: Câmara dos Deputados, Edições Câmara. 2013.

CURI, E. A Matemática e os professores dos anos iniciais dos anos iniciais. São Paulo: Musa Editora. 2005.

ESTEVE, J.M. Mudanças Sociais e função docente. NÓVOA, A. (Org.). Profissão professor. Porto: Porto Editora. 2014.

FALSARELLA, A.M. Formação continuada e prática de sala de aula: os efeitos da transformação continuada na atuação do professor. Campinas, São Paulo: Autores Associados. 2004.

FREIRE, P. Pedagogia da autonomia: saberes necessários à Prática Educativa. 41 ed. São Paulo: Paz e Terra. 2014.

GATTI, B. A. (coord.); BARRETTO, E.S.S. Professores do Brasil: impasses e desafios. Brasília: UNESCO. 2009.

GATTI, B.A. Formação de professores no Brasil: características e problemas. In: Revista Educação \& Sociedade. Campinas: v. 31; n.113.Disponível na internet via http://www.scielo.br.php?pid=S0101-7330201000016\&script-sci_arttext. Arquivo capturado em 22/07/2015. 2010.

GATTI, B.A. Valorização da docência e avaliação do trabalho docente: o papel da avaliação participativa em um contexto institucional. In: GATTI, B.A. O trabalho docente: avaliação, valorização, controvérsias. (Org.). Campinas, SP: Autores Associados; São Paulo: Fundação Carlos Chagas. 2013.

GIL, A.C. Estudo de caso: fundamentação científica - subsídios para coletas e análise de dados - como redigir o relatório. São Paulo: Atlas. 2009.

GUÉRIOS, E. Espaços intersticiais na formação docente: indicativos para a formação continuada de professores que ensinam matemática. In: FIORENTINI, D; NACARATO, A.M. (Org.). Formação e desenvolvimento profissional de professores que ensinam Matemática. São Paulo: Musa Editora. 2005.

GUIMARÃES, V.S. Os saberes dos professores: Ponto de partida para a formação contínua. Boletim Salto para o Futuro, v.13, p. 33-38. 2005.

IMBERNÓN, F. Formação permanente do professorado: novas tendências. São Paulo: Cortez. 2009.

Formação continuada de professores. Porto Alegre: Artmed. 2010.

Formação docente profissional: formar-se para a mudança e a incerteza. 2. ed. São Paulo: Cortez. 2001.

JOSSO, M.C. Da formação do sujeito.... Ao sujeito da formação. In: NÓVOA, A. FINGER, M. (Org.). O método (auto) biográficos e a formação, Natal, RN: EDUFRN; São Paulo: Paulus. 2010. 
LIBERALI, F.C. Formação crítica de educadores: questões fundamentais. Campinas SP: Pontes. 2010.

LITWIN, E. Educação a distância: temas para debate de uma nova agenda educativa. Porto Alegre: Artmed Editora, 2001.

MARÇAL, L. M. P. C. L. A formação inicial dos educadores: professores e professoras. Rizoma Freireano. vol.12. Disponível na internet via http://www.rizomafreireano.org/index.php/a-formacao-inicial-dos-educadores-professores-e-professoraslena-maria-pires-coreia-lopes-marcal. Arquivo capturado em 10/08/2015. 2012.

MORAES, M.C. O paradigma educacional emergente. Campinas: Ed. Papirus. 1997. MORAES, R. GALIAZZI, M.C. Análise textual discursiva. ljuí: Ed. Unijuí. 2011.

MURTA, C. P.C; SILVA, D. M; CORDEIRO, V. L.S. Guia do Curso. In: BRASIL. Ministério da Educação. Secretaria da Educação Básica. Pró-Letramento: programa de formação continuada de professores dos anos/séries iniciais do ensino fundamental: matemática: fascículo do tutor e encartes. Brasília: MEC/SEB. 2008.

NEDER, M.L.C. A formação do professor a distância: desafios e inovações na direção de uma prática transformadora. Florianópolis: UFSC, Tese de doutorado. 2004.

NÓVOA, A. Professores: imagens do futuro presente. Educa: Lisboa, 2009.

SCHON, D.A. Educando o profissional reflexivo: um novo design para o ensino e a aprendizagem. Porto Alegre: Artmed. 2000.

VEIGA, I.P.A. Professor: tecnólogo de ensino ou agente social. In: VEIGA, I.P. A. AMARAL, A.L. (Org.) Formação de professores: políticas e debates. Campinas, SP: Papirus. 2014.

YIN, R.K. Estudo de caso: planejamento e métodos. Porto Alegre: Bookman. 2005.

Submissão: 05/07/2017

Aceite: 19/06/2018 